\title{
Correction to: Analysis of clinical features of RPE adenoma
}

\section{Nan Zhou ${ }^{1} \cdot$ Xiaolin $\mathrm{Xu}^{1} \cdot$ Wenbin Wei ${ }^{1}$}

Published online: 25 June 2020

(C) Springer-Verlag GmbH Germany, part of Springer Nature 2020

\section{Correction to: Graefe's Archive for Clinical and Experimental Ophthalmology https://doi.org/10.1007/s00417-020-04784-8}

In the original version of our paper entitled Analysis of clinical features of RPE adenoma published in Graefe's Archive for Clinical and Experimental Ophthalmology. Published online: 13 June 2020. The corresponding author's name of the article is Wenbin Wei, but it was misspelled as Weibin Wei.

The original article has been corrected.

Publisher's note Springer Nature remains neutral with regard to jurisdictional claims in published maps and institutional affiliations.

The online version of the original article can be found at https://doi.org/ 10.1007/s00417-020-04784-8

Wenbin Wei

weiwenbintr@163.com

Nan Zhou

echo99time@163.com

Xiaolin Xu

drxuxiaolin@163.com

1 Beijing Tongren Eye Center, Beijing Key Laboratory of Intraocular Tumor Diagnosis and Treatment, Medical Artificial Intelligence Research and Verification Laboratory of the Ministry of Industry and Information Technology, Beijing Tongren Hospital, Capital Medical University, Beijing, China 